\title{
Study on the Teaching of College English Autonomous Learning Based on Constructivism
}

\author{
H.M. Zhao \\ Teaching and Research Institute of Foreign Languages \\ Bohai University \\ Jinzhou, China
}

\begin{abstract}
With the coming of knowledge economy era, the knowledge that people learn in the college has been far from enough to meet the needs of the workplace, so the people need to learn the knowledge for lifetime. It becomes the key point of English education reform that how to improve the autonomous learning ability and cultivate the English comprehensive ability for college students. However, this problem can be well solved by the college English teaching based on the constructivism. In this paper, the author discusses the strategies on autonomous English learning as based on the constructivism, and hopes to be useful to improve the autonomous English learning ability for college students.
\end{abstract}

Keywords-autonomous learning; constructivism; English ability; learning strategy

\section{INTRODUCTION}

With the further development of China' s market economy, the social demand for English talents is more and more strict. It requires the students to have high English abilities on listening, speaking, reading and writing. At the same time, the arrival of knowledge economy age requires that people should not only learn knowledge in college stage, but also learn knowledge in their lifetime. Currently, the college English education still stays in the traditional teaching mode, that is, the teacher gives the lecture and the students passively accept the knowledge. The enthusiasm of English learning is generally low for the students and they are weary of learning English. At the same time, the long-term passive learning leads to the low autonomous learning ability for students and they do not actively and autonomously learn English, therefore, their ability can not meet the market demands. The cause of this phenomenon lies in the fact that the traditional education mode ignores the subjective role of students in learning, and therefore does not fully exert the initiatives of the students. The passive learning leads to the disjointing of teaching and learning, and thus the teaching effect is not ideal. It becomes the focus of English education reform that how to change the obsolete state of current college English education and improve the autonomous learning ability and the comprehensive English ability for college students. Fortunately, the teaching mode of college English autonomous learning based on the constructivism can well change the status of current English teaching and improve the initiatives and enthusiasm of students. Therefore, it can change the status of wearing of English learning and improves the comprehensive English ability for the students.

\section{LEARNING VIEW OF CONSTRUCTIVISM}

Constructivism holds that although the world is an objective existence, the understanding of the world and the meaning is decided by the individual and it is much different for different people. And the man's understanding on the world is always based on the experience of his own. Therefore, the understanding on the external world is different for individuals. The knowledge is not simply passed on to the students by the teacher, but is constructed by the students themselves. The construction of knowledge is not the passive process, but the active process and can not be replaced by others. Learning should be the construction of two aspects of meaning. One is the meaning construction of new information; the other is the reorganization and transformation of the original experience. The learner always understands and constructs new knowledge and information by his own experience. Therefore, the learning process is not the one to accept the information passively, but to construct the meaning actively. The learner takes the initiative to choose, treat and process the information, so as to obtain their meanings. To obtain the meaning, the learner must re-understand and code the new information according to his original experience and knowledge, and then constructs his understanding. In this process, the original knowledge of learner is adjusted due to absorbing of new knowledge and information. Thus the constructivism cares how to construct the new knowledge according to their previous experience, psychological structure and beliefs.

Constructivism stresses the initiative, sociality and situation of learning. It puts forward many new opinions on learning and teaching as follows. (1) Each one has the different understanding on the new knowledge, so we should strengthen the cooperation between students. This enables the students to learn from others. Therefore, collaboration in learning is recommended by constructivism. (2) The teacher should well know the knowledge level of students and avoids the rote learning mode in class. The learning should be based on the previous level of knowledge for the students. (3) The role of teacher is not to transfer knowledge to the students, but to provide counsel to the students. The teacher becomes the learning partner or cooperator of students. The teacher promotes the students to construct the meaning of knowledge, not just provides and instills the knowledge to the students. The students are the main bodies of learning knowledge and sponsors of constructing knowledge.

\section{CONCEPTS OF AUTONOMOUS LEARNING}

The traditional learning mode overemphasizes the acceptance and mastery of students while ignores the discovery and exploration, therefore, leads to the extreme treatment to the 
learning process of students. This compels the students to accept the knowledge from textbooks directly. The learning of students becomes the passive acceptance and memory. This teaching mode ignores the main body state of students in learning and seriously impedes the students' learning initiative and enthusiasm, and this consequently causes the weariness of learning English.

Cultivation of autonomous learning ability can help to improve the learning efficiency in class and improve the comprehensive ability of students. This is necessary for teaching. Holec made a more accurate definition of autonomous learning, namely, the learning ability that can be responsible for the students themselves.[1] The learners determine their own goals in learning as well as the content and progress of learning. The learners choose the learning methods and skills, and monitor and evaluate the learning process. The autonomous learning ability is not innate, but acquired through conscious training. Autonomous learning is not the case that the students learn by themselves and do not need the teacher. It means that the students do not blindly follow the teacher, and do the preparation before class and actively participate in class and go over the lessons after class. In these processes, the students take the initiatives and depend on themselves. This changes the passive learning to active learning.

The factors that affect autonomous learning can be listed as follows. (1) Self-efficacy. The individuals believe they have the ability to accomplish a certain task. Thus self-efficacy is the self-confidence of learner shown in the activities. In learning, students with strong self-efficacy usually have strong autonomous learning ability and can actively complete a variety of learning tasks. While the students with poor selfefficacy has poor ability of autonomous learning. Therefore, the students with strong self-efficacy usually set higher learning goals in their learning and the ability of selfadjustment is also strong. The effect of self-efficacy and goal setting in autonomous learning is shown in Fig. 1.

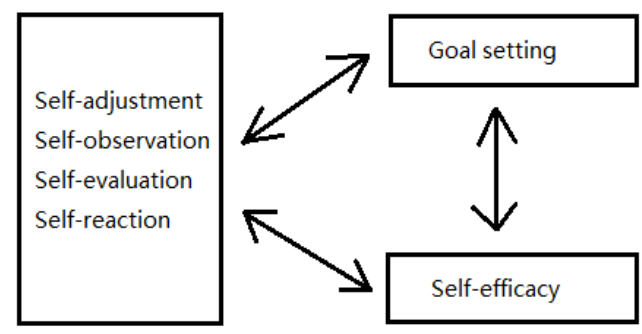

\section{FIGURE I. SOCIAL COGNITIVE PROCESS IN AUTONOMOUS LEARNING}

Goal setting. Whether the goal setting is appropriate can affect the motivation of autonomous learning. Appropriate goal setting can enhance the confidence of students and further improves the sense of self-efficacy. Improper goal can frustrate the students and leads to the loss of confidence in autonomous learning.

Cognitive strategies and metacognitive strategies. The cognitive strategies can improve the efficiency of students' autonomous learning, and enhance their confidence of learning. While the metacognitive strategies can help the students to strengthen the self-supervision and self-adjustment, which can deal with the difficulties encountered in autonomous learning. [2]This can promote the autonomous learning.

\section{TEAching Strategies OF AutonOmous LEARNing BASED ON THE CONSTRUCTIVISM}

i. The teaching should be learner-centered and the autonomous learning situations must be created. Constructivism holds that knowledge structure is essentially constructed by individuals rather than instructed by others. The knowledge construction is produced in social interaction. The main body of learning is the leaner. For language learning, the learner can acquaint the knowledge and improve the communication ability through much practice. Therefore, English teaching should be learner-centered and the class should be interactive. The teacher acts as the organizer, instructor, helper and promoter of students in autonomous learning. Situational teaching is an important factor in the constructivism view of learning. The teacher should create a realistic situation in which the students are arranged to complete the learning task. In learning, the students should communicate with others and jointly cope with difficulties in learning. The teacher guides the students timely when they encounter the difficulties. The teacher also provides the students more learning materials and guides them to discover and solve the problems.

ii. Play the subjective initiative of students and promote collaborative learning. Constructivism emphasizes that the teaching should be learner-centered and plays the initiative of students. The students should actively participate in the class teaching and construct the knowledge structure autonomously. In teaching, the teacher should make full use of the technology of multimedia and network to guide the learning of students. Before class, the teacher gives a related topic to the students and asks the students to search for the relevant information and discuss the topic. The main purpose is to arouse the enthusiasm and interest of students and make them learn actively. In class, the teacher puts the main content of section into the share file of internet and meanwhile asks the questions and organizes the students to discuss in group. The students collaborate to solve the problems. For those difficult problems, the teacher guides the students to search for the information through the Internet. Finally, the teacher summarizes the answer of question and leaves the homework to students.[3]

iii. Set a reasonable goal of learning and improve selfefficacy. Constructivism believes that the construction of knowledge should be based on the experience and the previous knowledge structure of students. Too difficult knowledge does not help to the knowledge construction of students. Therefore, the teacher should design their teaching content according to the learning ability of students and guides the students to learn actively. The teaching goal should be adjusted according to the learning ability of students. For the students with poor learning ability, the learning goal should be set relatively lower, so that the students can successfully complete the learning goal. This benefits the students to improve the self-efficacy. For the students with strong learning ability, the learning goal is also 
set higher. At the same time, the teacher should help the students to complete the learning goal and let them experience the feeling of success, which can improve the self-efficacy of students.

iv. The teacher should cultivate the students' awareness and motivation of language learning. Both consciousness and motivation are the important factors for autonomous learning, and they are also the important psychological factors that limit the learning. The cultivation of autonomous learning ability is just a joke without the consciousness and motivation of learning. The motivation of learning is the impetus to maintain and promote the learning activities. The motivation of English learning is the desire to learn English, which is the mental states of self-consciousness and enthusiasm of students. Awareness and motivation of autonomous learning depend on the intrinsic motivation and self-confidence of students, as well as the level of knowledge and skills of students. For the college students, it is important to realize that the autonomous learning ability is mainly cultivated by the students themselves. English can be strengthened and improved by much language practice, which can not be replaced by the class teaching. Nevertheless, the cultivation of both consciousness and motivation of autonomous learning should depend on the teacher. The teacher should help the students to strengthen the motivation of learning according to their interests, English levels, intelligence factors and cognitive ability. The teacher should help the students to overcome the negative factors such as shyness, timidity, anxiety and fear. Outside class, the teacher should encourage the students to actively participate in the English club, listen to the English broadcasting and communicate with foreigners. [4]

v. Strategies on the cultivation of autonomous learning. To perform autonomous learning successfully, the learners must master certain learning strategies and effectively use the language learning strategies. The ability of autonomous learning depends on the use of learning strategies. It is the key to improve the ability of autonomous learning through appropriate learning strategies. The learning strategies can be divided into cognitive strategies and metacognitive strategies. By teaching of cognitive strategies, the students can understand and master the skills and strategies of learning, such as listening skills, reading skills, writing skills and translation skills. By teaching of metacognitive strategies, the students develop the habits of setting study plan, arranging learning tasks, monitoring learning and evaluating the completion of tasks. Thus the students gradually develop the ability of autonomous learning. Through teaching of cognitive strategies, the students learn to master the skills of English. Through teaching of metacognitive strategies, the students learn to arrange their language learning. Therefore, it becomes an important part of English teaching that the teacher helps the students to choose and master the appropriate strategies of autonomous learning.

vi. The teacher instructs the students to construct the knowledge actively. Good teaching mode of autonomous learning is always learner-centered. The teaching content can provide the students with the opportunities of choice, thinking, cooperation and knowledge construction. Teaching should be carried out in the situation that the teacher and students collaborate in equal status. In most time, the teacher interacts with the students and inspires them. Generally, the learning process is the one that students construct the knowledge structure actively and master the knowledge completely. In this process, the teacher usually inspires and guides the students to learn rather than imparts the knowledge simply. Therefore, the teacher should create the situation in class teaching, puts forward the questions and arouse the interests of students and let them think about the questions. The teacher hints the cues of questions to the students rather than simply tell the answers. Then the teacher asks the students to solve the questions via communicating with other students. Finally, the teacher should evaluate on the solving situation of questions. In the whole teaching activity, the teacher guides the students to construct the knowledge structure actively.[5]

\section{CONCLUSION}

Due to the coming of knowledge economy, the learning of knowledge for college students has been lasting for lifetime. Therefore, it is necessary to cultivate the autonomous learning ability of students. Constructivism suggests that the teacher should change the cramming mode of teaching, and fully play the initiative of students in teaching, guides the students to think about the question and construct the knowledge structure. At the same time, the teacher should concentrate on the goal setting and teaching content which must be appropriate for the students. In the teaching, the teacher intends to cultivate the self-efficacy as well as the learning strategies and awareness of students. This would be helpful to the improvement of autonomous learning ability.

\section{REFERENCES}

[1] Holec, H. Autonomy and Foreign Language Learning. Oxford: Pergamon Press, 1981.

[2] Wenden, A.L. Learner Strategies for Learner Autonomy. London: Prentice Hall, 1998.

[3] Warschauer, M. Turbee, L. \& Roberts, B. “Computer learning networks and student empowerment” . System 24 (1), 1-14. 1996.

[4] Williams, M. \& Burden, R, Psychology for Language Teachers. Cambridge: Cambridge university press, 1997.

[5] O' Malley, J. M. \& Chamot, A.U., Learning strategies in second language acquisition. Cambridge University Press,1990. 